\title{
Solução de conflitos: Acordo ou sentença
}

\section{Conflict resolution: Agreement or judgment}

Resolución de conflictos: Acuerdo o juicio

Isabel Lima dos Santos Oliveira

ORCID: https://orcid.org/0000-0002-0018-0326

Escola da Magistratura de Rondônia, Brasil E-mail: isabelsantos@tjro.jus.br

Renato Lima dos Santos

ORCID: https://orcid.org/0000-0001-8306-3821 Centro Universitário Aparício Carvalho FIMCA, Brasil E-mail: renato.fbt@gmail.com

Alex Gomes Pereira

ORCID: https://orcid.org/0000-0003-3563-4161 Centro Universitário São Lucas, Brasil E-mail: alexgp885@gmail.com

Fábio Herrera Fernandes

ORCID: https://orcid.org/0000-0003-3242-8303 Centro Universitário São Lucas, Brasil E-mail: fabio26012002@gmail.com

Rafael Luis da Silva

ORCID: https://orcid.org/0000-0002-9485-479X Centro Universitário São Lucas, Brasil E-mail: rafael.luis@ saolucas.edu.br

Marcus Vinicius Oliveira Braga

ORCID: https://orcid.org/0000-0001-9965-8125 Centro Universitário São Lucas, Brasil E-mail: marcus.braga@saolucas.edu.br

\begin{abstract}
Resumo
Novas formas de flexibilização das relações de trabalho têm se disseminado, dentre as quais a autocomposição, que se estabelece dentro dos tribunais brasileiros como uma solução para dirimir o problema da morosidade na tramitação e procedimento processuais. Com o advento da resolução 125/10, que objetiva a utilização de novas formas de solução de conflitos, voltadas à construção do consenso, bem como da Lei n ${ }^{\circ} 13.105$, de 16 de março de 2015, O Novo CPC, que trouxe diversas inovações ao sistema processual brasileiro e uma das que mais chamam a atenção é justamente a audiência de conciliação. Um novo horizonte se constituiu. Surge assim, a perspectiva da institucionalização da obrigatoriedade da autocomposição. Propõe-se que além de amenizar a morosidade processual, ascende o acesso à justiça e vem para modificar a cultura da sentença, no sentido de que é oportunizado às partes, a resolução de suas lides, onde a um terceiro imparcial é imposta a missão de tentar aproximar os interesses de ambas, orientando-as na formação de um acordo, sem fugir aos princípios norteadores do processo. O judiciário tem tomado diversas iniciativas para acomodar-se a tais mudanças. $\mathrm{O}$ estudo tem como objetivo principal a análise das vantagens entre o acordo na audiência de conciliação ou a espera de uma decisão na sentença judicial, verificando se o tempo processual em ambos os casos. Além do mais, a conciliação tem como objetivo buscar o modo mais célere de resolver a controvérsia, possibilitando um maior acesso à justiça.
\end{abstract}

Palavras-chave: Danos morais; Conciliação; Acordos; Solução de conflitos; Sentenças.

\begin{abstract}
The advancement of information and communication technology and society changes, new forms of flexible work relations have been disseminated, among which the Self-composition establishes itself within the Brazilian courts as a solution to resolve the problem of delay in processing and procedural procedure. With the advent of the $125 / 10$ resolution, aimed at the use of new forms of conflict resolution, aimed at consensus-building, as well as of law $\mathrm{n}^{\circ}$ 13,105, of 16 March 2015, the new CPC, which brought several innovations to Brazilian and one of the procedural system that more attention is precisely the conciliation hearing. A new horizon is formed. Arises like this, the perspective of institutionalization of compulsory Self-composition. It is proposed that in addition to lessen the length of procedure is access to justice and comes change the culture of the sentence, in the sense that is provided to the parties, the resolution of your deal, where a. Third party is required to try Approaching the interests of both, guiding them in the formation of an agreement, without departing from the guiding principles of the process. The judiciary has taken various initiatives to accommodate such changes. The main objective of the study is to analyze the advantages
\end{abstract}


between the agreement in the conciliation hearing or the waiting for a decision in the judicial sentence, verifying the procedural time in both cases. Moreover, conciliation aims to find the fastest way to resolve the controversy, allowing greater access to justice.

Keywords: Moral damages; Conciliation; Agreements; Solution of conflict; You're sorry.

\section{Resumen}

Nuevas formas de flexibilización de las relaciones laborales, entre las que se encuentra la autocomponencia, que se establece dentro de los tribunales brasileños como una solución para resolver el problema de la lentitud en el procedimiento y procedimiento. Con la llegada de la resolución 125/10, que tiene por objeto el uso de nuevas formas de resolución de conflictos, destinada a construir consensos, así como la Ley $\mathrm{N}^{\circ} 13.105$ de 16 de marzo de 2015 , El Nuevo CPC, que trajo varias innovaciones al sistema procesal brasileño y una de las más llamativas es precisamente la audiencia de conciliación. Se ha formado un nuevo horizonte. Por lo tanto, surge la perspectiva de la institucionalización de la autocomponición obligatoria. Se propone que además de suavizar la lentitud procesal, el acceso a la justicia se levante y venga a modificar la cultura de la sentencia, en el sentido de que es oportunista para las partes, la resolución de sus párpados, donde se impone al tercero imparcial la misión de tratar de traer los intereses de ambos, guiándolos en la formación de un acuerdo, sin escapar de los principios rectores del proceso. El poder judicial ha tomado varias iniciativas para dar cabida a estos cambios. El objetivo principal del estudio es analizar las ventajas entre el acuerdo en la audiencia de conciliación o la espera de una decisión en el auto judicial, verificando si el tiempo procesal en ambos casos. Además, la conciliación tiene como objetivo buscar la forma más rápida de resolver la controversia, permitiendo un mayor acceso a la justicia.

Palabras clave: Daño moral; Conciliación; Acuerdos; Resolución de conflictos; Oraciones.

\section{Introdução}

As relações interpessoais, de modo geral são construídas por interesses, entretanto é de se esperar que exista conflito entre esses interesses, isso faz com que se tenha necessidade de negocia-los. Nesse sentido, o CNJ, iniciou em 2004, um processo de consolidação das políticas públicas voltadas à resolução de conflitos, que resultou na aprovação da Resolução 125 .

No Brasil, ainda prevalece a cultura da sentença, que se valendo do inciso XXXV do art. $5^{\circ}$, que por muito tempo o acesso à Justiça era interpretado de forma restritiva, o que de certa forma traz prejuízo não só para quem está litigando, mas para sociedade como um todo, tendo em vista o congestionamento nos tribunais. Nesse contexto entra o NCPC, na expectativa de incutir a cultura da pacificação entre os litigantes do processo, onde dispõe, o parágrafo $2^{\circ}$ do artigo $3^{\circ}$ que: “ $O$ Estado promoverá, sempre que possível, a solução consensual dos conflitos".

Dentro da atual realidade, entra os meios alternativos de resolução de conflitos, tais como: Negociação, Mediação, Conciliação e Arbitragem, os quais necessitam de recomendação legal, por se tratar de conduta (costumes) social. No Brasil, a Conciliação dentre as técnicas de solução de conflito, é a mais difundida e tem sido utilizada como ferramenta de trabalho pelo Poder Judiciário, sendo apontada como opção de técnica alternativa de gestão de conflitos e pacificação social.

Ainda assim, as pessoas não têm noção de que os conflitos podem ser solucionados com o diálogo, tal fato, leva a uma inquietação. Nesse contexto, este estudo pretendeu responder ao seguinte questionamento: para quem é vantajoso um acordo, se para os requerentes ou para os requeridos?

Sob esse prisma, este estudo teve por objetivo geral evidenciar a dinâmica de comparar processos de ação por danos morais, solucionados por homologação de acordo, com os processos sentenciados, no período de janeiro a junho de 2017.

Entretanto, para facilitar a resolução de tal questionamento desmembrou-se o objetivo geral nos objetivos específicos no sentido de analisar os processos (relatórios) de ação por danos morais no período de janeiro a junho de 2017 , do juizado especial e Juizado especial cível de porto velho e apresentar os tramites do processo de conciliação, da distribuição à homologação do acordo e da distribuição à sentença, descrever as vantagens e desvantagens do processo conciliado, com acordo e do processo sentenciado.

Com isso acredita-se estar contribuindo com os debates jurídicos sobre a situação do congestionamento de processos nos tribunais, os quais possuem morosidade na tramitação. Nessa situação, pode ser notada a falta de observância da resolução 125, que objetiva a utilização de novas formas de solução de conflitos, voltadas à construção do consenso. 
Para o alcance destes objetivos realizou-se estudo no âmbito da CEJUSC, no Juizado Especial e Juizado Especial Cível do Tribunal de Justiça do Estado de Rondônia, tribunal reconhecido como o mais célere do Brasil. Vale esclarecer que o Poder Judiciário dispõe de uma estrutura organizacional formada por varas especiais e varas comuns. Nessa primeira, são atendidas as demandas processuais e pré processuais e atuam na prevenção, no tratamento e na solução de conflitos que versem qualquer matéria, judicializada ou não, sempre que admitida a solução da controvérsia por métodos consensuais.

'Com vistas na abordagem quantitativa dos dados, realizou-se a pesquisa, por meio de revisão sistemática nos relatórios estatísticos, (Freitas \& Prodanov, 2013) retrata que [...], essa fase exprime a conjuntura em que o investigante obtém os elementos coletados por meio da aplicação de técnicas de inquirição dispondo de artefatos singulares para o tipo de erudição que ambiciona, em anuência com o intento de inquérito analítico. Esses conjuntos de noções, após seu registro, são organizados e classificados de forma sistemática, passando pelas fases de seleção, codificação e tabulação, para o caso de pesquisas quantitativas

A pesquisa realizada contempla ações distribuída que findaram com acordo, com sentença ou continuadas, principalmente, relativos à danos morais. Na primeira parte da coleta dos dados foram buscadas referências bibliográficas a partir das diretrizes e normas que disciplinam as resoluções de conflito, em especial a Conciliação. Para o embasamento teórico revisitou-se a literatura, manuais apresentando conceitos, padrões, ideias e a visão de diferentes autores sobre o tema Conciliação. Partindo disso surgiu a necessidade de colher dados documentais, com os responsáveis pelos relatórios estatísticos na Cejusc especial e cível da Comarca de Porto Velho, por meio de constatação in loco sobre a tramitação dos processos.

Os processos, objeto do estudo, foram selecionados por amostragem probabilística sistemática. Esclarecendo esse procedimento de seleção, considerando-se o total de 5.145 Processos, arbitrou-se 357 deles, os quais foram definidos como objeto da análise. Os processos estudados estavam entre aqueles distribuídos durante os meses de janeiro a junho de 2017, cuja finalidade foi apontar para quem é vantajoso o acordo, se para o requerente ou para o requerido e, com base no referencial bibliográfico, apresentar sugestões de melhorias.

Assim, o estudo desenvolveu-se em duas fases, a primeira, na qual se teve a oportunidade de conhecer o ambiente em que se realizariam as análises, estabelecer contato com o Juiz Coordenador, Supervisora e Chefes da CEJUSC e divulgar o objetivo do estudo. A segunda fase consistiu-se na aplicação dos instrumentos de coleta dos dados, apurando-se o máximo de informações possíveis e analisando-se a dinâmica de comparar processos de ação por danos morais, solucionados por homologação de acordo, com os processos sentenciados, no período de janeiro a junho de 2017.

\section{Metodologia}

O desenvolvimento desta pesquisa se deu a partir do estatístico elaborado pelos chefes do centro de conciliação CEJUSC ESPECIAL E CÍVEL. O método de abordagem utilizado, foi o quali-quanti ou triangulação. Para a definição quanto à forma de abordagem da questão investigada, consideramos a afirmação de (Cooper \& Schindler, 2016), ao dizer que:

[...]. Em virtude a controvérsia já retratada, as perquirições qualitativas podem ser acordadas com os estudos quantitativos para amplificar a qualidade constatada da pesquisa, [...]

(Cooper \& Schindler, 2016) acrescenta, "ainda, que muitos pesquisadores reconhecem que a pesquisa qualitativa compensa a fraqueza da pesquisa quantitativa e vice-versa", o que se pretendeu nesta, justificando-se, portanto, a utilização da pesquisa quali-quanti no desenvolvimento deste estudo. Esta pesquisa teve um delineamento do tipo descritivo, com a função de apresentar características da população ou fenômeno estudado, afim de, a partir dos resultados encontrados, possibilitar a produção de outros conhecimentos. No entendimento de (Freitas \& Prodanov, 2013), os dados descritivos, [...]denotam a maior 
multiplicidade numérica possível de elementos efetivados na realidade estudada. Importa-se demasiadamente com o processo ao invés do produto. Na análise dos dados coletados, não há preocupação em comprovar hipóteses previamente estabelecidas, no entanto, estas não eliminam a existência de um quadro teórico que direcione a coleta, a análise e a interpretação dos dados.

É comum autores não diferenciarem abordagem quantitativa da qualitativa, assim, para a coleta de dados buscou-se os estatísticos elaborados, junto aos chefes imediatos dos conciliadores da CEJUSC DE Porto Velho/RO. Os requisitos técnicos que foram observados junto ao tema dividiram-se em três partes: A primeira tratou da exploração documental, que consistiu na revisão da literatura, manuais e levantamento de trabalhos de investigação disponíveis na internet. Essa etapa forneceu elementos teóricos que permitiu moldar o tema, revelar as suas dimensões essenciais e facetas peculiares, sugerindo caminhos e modos de abordagem para posterior sistematização. A síntese criteriosa das informações levantadas na etapa de exploração, a respeito do objeto de estudo visando converter-se num quadro teórico de referência para sustentação das conclusões, configurou-se na segunda parte. Na terceira parte realizou-se a tabulação e compreensão dos dados coletados na pesquisa de campo, a fim de dar suporte ao alcance dos objetivos formulados.

A população do estudo era grande para o curto prazo da pesquisa, assim, foi necessário definir uma amostragem que pudesse representar o todo, de acordo com (Gil, 2008) não foram verificados todos os integrantes da população, pois se usou procedimentos estatísticos para se definir uma amostra significativa e em quantidade suficiente de tal modo que os resultados obtidos são suficientes para representar o universo pesquisado, levando em conta a margem de erros calculada.

Decidiu-se que a pesquisa seria com os processos que tiveram tentativas de acordo, dentre os dos meses de janeiro a junho de 2017, neste período foram agendadas 10.270 audiências, conforme Tabela 1, que por motivos diversos não aconteceram.

Tabela 1. Processos com audiências agendadas.

\begin{tabular}{c|c|c|c}
\hline Mês & $\begin{array}{c}\text { Audiências agendadas e } \\
\text { não realizadas pela } \\
\text { ausência de uma ou de } \\
\text { ambas as partes }\end{array}$ & $\begin{array}{c}\text { Audiências agendadas e realizadas, } \\
\text { com tentativas de concilia, porém, } \\
\text { sem acordo (Juizados Especial/ } \\
\text { Especial Cível) }\end{array}$ & $\begin{array}{c}\text { Total de acordos } \\
\text { homologados }\end{array}$ \\
\hline Janeiro & 620 & 256 & 63 \\
\hline Fevereiro & 1.652 & 749 & 213 \\
\hline Março & 2.167 & 814 & 265 \\
\hline Abril & 1.531 & 573 & 227 \\
\hline Maio & 2.263 & 857 & 238 \\
\hline Junho & 2.037 & 725 & 1.171 \\
\hline Total & 10.270 & 3.974 & \\
\hline
\end{tabular}

Fonte: Autores.

É importante ressaltar que o Centro de Conciliação de Rondônia - CEJUSC ESPECIAL E CÍVEL, no prédio adaptado para esse fim, teve seus trabalhos iniciados em novembro 2016, por isso, a pesquisa trata somente dos 06(seis) primeiros meses de 2017. Assim, dos 5.145 processos, devido ao curto período de tempo para realização das análises, foi necessário definir uma amostra, conforme SILVA, 1997, P. 135, calculada através da equação 1.

Figura 1. Equação.

$$
\mathrm{n}=\frac{z^{2} p q N}{(N-1) E^{2}+Z^{2} p q}
$$

Fonte: Autores. 
Os cálculos foram realizados usando a fórmula em Excel, obtendo uma amostra de 357 processos, sendo que destes, 91 com acordo e 266, sem acordo, conforme Tabela 2.

Tabela 2. Amostragem.

\begin{tabular}{c|c}
\hline \multicolumn{2}{c}{ Amostra analisada } \\
\hline Com acordo & Sem acordo \\
\hline 91 & 266 \\
\hline
\end{tabular}

Fonte: Autores.

Assim, "Apenas as amostragens probabilísticas oferecem a probabilidade de generalizar os resultados da população da amostra para a população de interesse" (Cooper \& Schindler, 2016). A CEJUSC cível e especial de Porto Velho, teve os trabalhos iniciados em novembro de 2016, para pratica de conciliação, em obediência ao novo CPC, e a resolução 125, e tem se observado que, embora timidamente, nos meses de janeiro a junho de 2017 houve um crescimento na demanda da audiência de conciliação.

Esse crescimento poderia ser intensificado se houvesse maior adesão dos operadores do direito, visto que ainda há grande resistência por parte de alguns advogados, que consideram a audiência de conciliação, como simples proforma, esquecendo que uma das funções do Advogado é a negociação (Tartuce, 2016).Em relação aos processos analisados, alguns são distribuídos via atermação, que é um dos meios de acesso à Justiça pelos Juizados Especiais, em que o cidadão propõe uma ação independentemente de estar assistida por um advogado, outros são distribuídos via advogados ou defensoria Pública e em sua grande maioria a audiência de conciliação é marcada logo na distribuição. Em relação a quantidade de acordo para a quantidade de tentativas de conciliação ainda é pequena como pode ser visto no Gráfico 1, que somente $25 \%$ do total de processos da amostra, houve autocomposição.

Gráfico 1. Quantidade de processos com acordo X sem acordo.

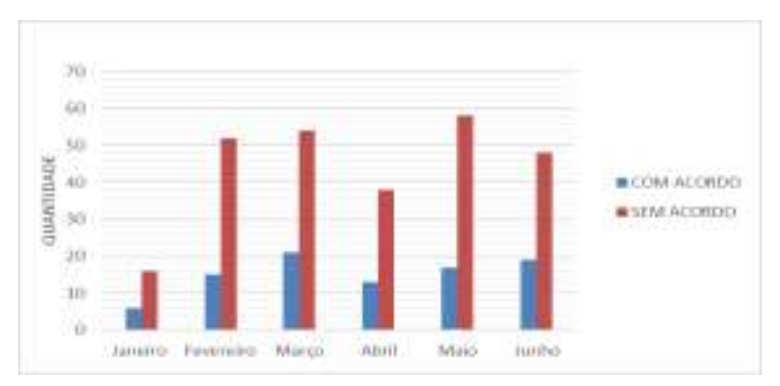

Fonte: Autores.

Outra leitura importante que pode ser feito a partir do gráfico, é que o número de não acordo é maior em $66 \%$ dos acordos, apesar dos não acordo trazerem prejuízos em relação ao tempo, que supera aproximadamente 7 (sete) meses até a sentença, cabendo ainda recursos, enquanto o processo com acordo tem um tempo médio de 3(três) meses. Além disso, tem os custos processuais, que não são cobrados do requerente, em havendo a autocomposição, tais analises são reforçadas nas palavras de (Tartuce, 2016), que diz: As conveniências de anuir de mecanismos transitórios as vias jurisdicionais são várias: obtenção de resultados rápidos, confiáveis, econômicos e ajustados as mudanças tecnológicas em curso; ampliação de opções ao cidadão, que teria justiça estatal por força da redução do número de processos em curso.

Apesar das vantagens relatadas acima, existe os processos que necessitam de provas, portanto encaminhados ao Juiz para prosseguimento do feito, com instrução pertinente, essa quantidade é ínfima que não é condição desestimulante da 
autocomposição. Tem-se, as sessões declaradas "infrutífera", que mesmo não sendo celebrado um acordo em audiência, coloca as partes em diálogo, o que leva muitas vezes a um acordo extrajudicialmente. De acordo com os dados levantados, 9,78\% dos processos, tiveram a sentença com petição inicial improcedente, situação em que não pode ser tratado na conciliação.

\section{Resultados e Discussão}

Existe Diversos Conceitos para danos morais, mas no final todos chegam ao senso comum, de que "são as perdas sofridas por um ataque à moral e à dignidade das pessoas, caracterizados como uma ofensa à reputação da vítima. Qualquer perda que abale à honra pode ser caracterizada como dano moral. Moral (substantivo) é uma parte da filosofia que trata dos costumes, dos deveres e do modo de se comportar das pessoas, nas relações com seus semelhantes.

O dano moral é classificado pela doutrina, em dano direto ou dano indireto, considerando a causalidade entre o dano e o fato. O dano moral direto, é quando há lesão específica de um direito intangível, conforme preconiza a Professora Maria (Diniz, 2015): Danos morais diretos incluem danos aos interesses de ativos legais fora do balanço que se destinam a satisfazer ou desfrutar direitos da personalidade (como vida, integridade física e psicológica, liberdade, honra, etiqueta, intimidade e direitos emocionais). Sentimentos, a própria imagem) ou atributos da pessoa (como nome, habilidade, situação familiar). Abrangendo também, Danos à dignidade humana (CF/88, art. $1^{\circ}$, III).

Portanto, o que difere o dano moral direto do indireto são os efeitos da lesão, bem como, a repercussão que esta teve sobre o ofendido e seus bens tutelados, nesse sentido, o ministro Massami Uyeda, no Recurso Especial $n^{\circ} 1.129 .881 / R J$ relatou o seguinte: "Não há perda moral além da extrema dor ou humilhação do contratante em circunstâncias especiais. Isso porque o desconforto inerente às expectativas frustradas decorrentes da quebra de contrato foi inserido no cotidiano das relações comerciais, e não significa dano à reputação ou violação da dignidade humana."

Antes do Novo Código de Processo Cível, a lei não dispunha de elementos objetivos, quanto ao valor da indenização por danos morais, esse procedimento era de caráter subjetivo, cabia ao Juiz o poder discricionário de valorar a indenização, sob o prisma do princípio do livre convencimento do juiz. Com o advento do Novo Código de Processo Civil/2015, houveram mudanças em relação ao valor da causa, agora cabe ao autor, na sua petição inicial, atribuir à causa o valor pecuniário do dano moral pretendido, conforme art. 292, inciso V, NCPC, “O valor da causa constará da petição inicial ou da reconvenção e será na ação indenizatória, inclusive a fundada em dano moral, o valor pretendido.

Nos primórdios os conflitos eram solucionados, por meio da autotutela ou autodefesa, o que valia era a imposição do mais forte, método este, que se tornou crime no ordenamento brasileiro. Com o passar do tempo, o Estado monopolizou a jurisdição e a solução de conflitos que passou a ser promovida por meio de processo judicial, nas formas de arbitragem, negociação, conciliação e mediação.

A palavra conciliar, é um verbo que no dicionário significa, harmonizar, tranquilizar, adequar ou ajustar. O CNJ, criou em 2016, o manual de Mediação Judicial, onde trouxe conceituações simples, porém, funcionais, e a respeito da conciliação temos (acesso, 2017, p.21,22,23): A mediação pode ser definida como um processo breve de auto-organização em que um terceiro neutro em relação ao conflito ou um grupo de especialistas não interessado no assunto auxilia as partes ou partes relacionadas, e os auxilia por meio de tecnologia apropriada. Para chegar a uma solução ou acordo.

Originalmente, estabeleciam-se diversos pontos de distinção entre a mediação e a conciliação, sugerindo-se que, nos aspectos I: II; III e IV:

I) a mediação visaria à 'resolução do conflito' enquanto a conciliação buscaria apenas o acordo;

II) a mediação visaria à restauração 22 da relação social subjacente ao caso enquanto a conciliação buscaria o fim do litígio;

III) a mediação partiria de uma abordagem de estímulo (ou facilitação) do entendimento enquanto a conciliação permitiria a sugestão de uma proposta de acordo pelo conciliador;

IV) a mediação seria, em regra, mais demorada e envolveria diversas sessões enquanto a conciliação seria um processo mais breve com apenas uma sessão; 
V) a mediação seria voltada às pessoas e teria o cunho preponderantemente subjetivo enquanto a conciliação seria voltada aos fatos e direitos e com enfoque essencialmente objetivo;

VI) a mediação seria confidencial enquanto a conciliação seria eminentemente pública;

VII) a mediação seria prospectiva, com enfoque no futuro e em soluções, enquanto a conciliação seria com enfoque retrospectivo e voltado à culpa;

VIII) a mediação seria um processo em que os interessados encontram suas próprias soluções enquanto a conciliação seria um processo voltado a esclarecer aos litigantes pontos (fatos, direitos ou interesses) ainda não compreendidos por esses;

IX) a mediação seria um processo com lastro multidisciplinar, envolvendo as mais distintas áreas como psicologia, administração, direito, matemática, comunicação, entre outros, enquanto a conciliação seria unidisciplinar (ou monodisciplinar) com base no direito.

Como salienta (Goldberg, 2020), na proposta de aumentar a velocidade da justiça, a fim de melhorar a morosidade do sistema judiciário e manter a semelhança dos participantes no conceito de medição ganha-ganha (digital), a proposta visa desenvolver um acordo duradouro quando as duas partes chegam a um consenso, $\mathrm{O}$ que é benéfico para ambas as partes. O mediador pode reduzir o prazo e submetê-lo ao juiz para certificação, quer se trate de métodos pré-processuais ou processuais, pode tornar-se título judicial.

Esse interim, Scavone conceitua conciliação como um processo consensual breve, onde envolve conflitos de menos complexidade, no qual as partes ou os interessados são auxiliados por um terceiro, no caso o conciliador, que sem interesse na causa, usa das técnicas para tentar chegar a uma solução ou acordo, onde poderá sugerir uma solução, mas nunca a impor, (Scavone, 2014) Na mediação, embora o mediador proponha uma solução, ele não pode fazer cumprir sua proposta porque ela permite árbitros ou juízes. Por outro lado, procura fazer com que as partes aceitem suas considerações e escolhas para a resolução de conflitos, que devem ser adotadas espontaneamente por elas. Em suma, na mediação, se não houver acordo entre as partes, não há solução.

No que diz respeito a utilização de técnicas na conciliação, pressupõe-se que os profissionais seguem os princípios norteadores dos métodos dispostos no Código de Ética da Resolução 125 de 29/11/2010:

Confidencialidade: No processo de mediação, todo o conteúdo trazido, gerado e discutido entre as partes é limitado ao processo; Justiça: O mediador não apoia nenhuma das partes; Voluntário: se as partes quiserem, elas continuarão a mediar; A autonomia das partes: a decisão final, seja qual for a decisão, cabe inteiramente às partes, não havendo direito impositivo de decisão do mediador e do mediador.

A interpretação bem construída, não despreza os princípios, que irão influir no conteúdo e alcance de todas as normas, seu uso é de extrema importância para o sistema jurídico, é a base para a construção do processo. O princípio da legalidade é também denominado princípio da autonomia da vontade, ou seja, não se limita ao conteúdo da solução consensual do conflito, valendo também para o procedimento da conciliação e mediação, nesse seguimento o $§ 4$. do art.

Assim, os princípios merecem atenção, por se tratar de instrumentos que possuem real valor no que tange a ordem jurídica. De acordo com (Montai \& Miarelli, 2012) mesmo quando um magistrado se depara com uma lei em branco ou inexplicável que precisa ser defendida, ele deve proceder com cautela para que tal explicação busca-se primeiro a intenção do legislador, além de ser sempre orientada pelos princípios jurídicos gerais ou específicos. E é nesse aspecto que reside à eficácia dos princípios: como toda e qualquer norma jurídica deve a eles respeitar, sua eficácia é plena. A Conciliação como todo assunto jurídico, é regido por princípios, que são as colunas que edificam e sustentam este meio, percebe-se, portanto, a importância da identificação e do estudo dos princípios gerais e os fundamentais, aplicáveis aos processos alternativos de solução de conflitos, como diretrizes que devem ser observados.

O novo CPC, já no seu início faz referência a conciliação, artigo $3^{\circ}$ e $\S s:$

“Art. $3^{\circ}$ Não se excluirá da apreciação jurisdicional ameaça ou lesão a direito. $\S 1^{\circ}$ É permitida a arbitragem, na forma da lei. $\S 2^{\circ}$ O Estado promoverá, sempre que possível, a solução consensual dos conflitos. $\S 3^{\circ} \mathrm{A}$ conciliação, a mediação e outros métodos de solução consensual de conflitos deverão ser estimulados por Juízes, advogados, defensores públicos e membros do Ministério Público, inclusive no curso do processo judicial. 
Esse ato será obrigatório, no procedimento comum, tanto para o autor quanto para o réu, pois a ausência injustificada acarretará na aplicação de multa, por ato atentatório à dignidade da justiça. O prazo para defesa, somente será iniciado no caso de não realização de acordo entre as partes, tendo em vista que havendo acordo, encerra-se o processo, art. 334, II; $\S 8^{\circ}$ : “ $\S 8^{\circ}$ O não comparecimento injustificado do autor ou do réu a audiência de conciliação, e considerado ato atentatório à dignidade da justiça e será sancionado com multa de até dois por cento da vantagem econômica pretendida ou do valor da causa, revertida em favor da União ou dos Estados".

Em conformidade com (Goldberg, 2020) certas resoluções são de fato "ganha-ganha"; é quase inaceitável para uma ou ambas as partes, mas de certo modo, é melhor do que uma perspectiva de uma batalha continua ou um confronto judicial. Em contrapartida as partes poderão nomear por procuração seus advogados ou parente, ou abrir mão da audiência de conciliação e ou mediação, se assim o quiserem, o que deverá ser feito, ainda na petição inicial, conforme reza o artigo 334 e seus §s: “Art.334.

Se a petição inicial preencher os requisitos essenciais e não for o caso de improcedências liminar do pedido, o Juiz designara audiência de conciliação ou de mediação com antecedência mínima de 30 (trinta) dias, devendo ser citado o réu com pelo menos 20(vinte) dias de antecedência" [...]. §4 A audiência não será realizada: I - Se ambas as partes manifestarem, expressamente, desinteresse na composição consensual; II - Quando não admitir a autocomposição. § $5^{\circ} \mathrm{O}$ autor deverá indicar, na petição inicial, seu desinteresse na autocomposição, e o réu deverá fazê-lo, por petição, apresentada com 10(dez) dias de antecedência, contados da data a audiência.

Ainda, neste contexto existe a figura do preposto que representa a pessoa jurídica, mas sem vínculo empregatício ou qualquer poder de gestão ou mesmo uma pessoa representando uma Instituição Pública à qual pertence, mas sem poderes, devido as amarras com as Normas Externas, nas palavras de (Tartuce, 2016) Na reunião de consulta, a existência de entidades vinculadas a instituições da administração pública com a presença de representantes impõe restrições e condicionantes à autonomia dos mediadores ou participantes da mediação. No entanto, isso não significa que uma solução de consenso não seja viável. No que diz respeito à previdência, a particularidade de ser agente de órgão público em contenciosos reiterados confere particularidade a essas limitações.

Dentre as vantagens da conciliação, a participação das partes, na decisão da lide, opinando e decidindo, sem que haja vencedores ou vencidos, talvez seja a mais importante, junto com a celeridade processual e a paz social, que é um dos grandes motivadores da conciliação. Outra vantagem bastante apregoada na conciliação é a economia de tempo e dinheiro, tendo em vista que as partes não gastam com documentos, produção de provas e custas judiciais e ainda resolvem tudo na audiência de conciliação sem que o processo se alongue ocasionando idas e vindas aos fóruns (adaptado do conciliar é legal, queroconciliar-esclareça-suas-duvidas-Acesso 08/07/2017), completa (Tartuce, 2016), As vantagens de utilizar mecanismos alternativos dentro da jurisdição são várias: a obtenção de resultados económicos rápidos e fiáveis e a adaptação às mudanças tecnológicas em curso, o alargamento do direito de escolha aos cidadãos, à medida que diminui o número de litígios em curso, os cidadãos desfrutando do direito à justiça nacional. É um elemento importante destinado a permitir que a outra parte cumpra voluntariamente certas iniciativas. Quando as pessoas competirem com seus próprios desejos para estabelecer canais de produção para os dois, irão atender espontaneamente aos ajustes acordados.

A efetivação da conciliação nos processos judiciais como todo procedimento, acarretam algumas desvantagens como bem descreve, Cristiane Rodrigues Iwakura, no artigo publicado em 07/2010, (acesso 08/07/2014). A OWEN FISS considerou as desvantagens do acordo judicial. Para ele, o acordo será uma rendição às condições das massas, e essa condição não deve ser incentivada ou valorizada. Assim, a FISS afirma que a primeira desvantagem do acordo reside na sua própria origem, pois na maioria dos casos a celebração do acordo é motivada por vários fatores desfavoráveis, nomeadamente, atrasos judiciais, elevados custos processuais e má qualidade da jurisdição (devido ao excesso de demanda e à falta de infraestrutura adequada no Judiciário) e, por fim, o impacto social dos procedimentos processuais. (Iwakura, 2010) também salienta, que por causa 
desses fatores negativos, não é incomum que uma das partes ou mesmo ambas as partes cheguem a um acordo prejudicial. $\mathrm{O}$ compromisso do acordo será uma lacuna pontual intimamente ligada à pesquisa de mediação, pois a ocorrência da mediação impede o conforto social, que é o objetivo das disposições jurisdicionais e da utilização de mecanismos alternativos para a resolução de conflitos.

Algum processo, por sua natureza, é vantajoso passar pelo crivo do Juiz, a exemplo, situação de grande desigualdade entre os litigantes, caso em que o Juiz poderá aplicar os princípios e os valores constitucionais, por meio de decisão, assim explica (Tartuce, 2016), Sob algumas perspectivas, especialmente diante da severa desigualdade entre os litigantes, é importante utilizar o sistema judicial para que os juízes possam liderar a proteção de interesses socialmente relevantes e garantir a igualdade entre as partes. Outra vantagem importante do uso do sistema judiciário é a possibilidade de coação de pessoas que violam ordens de órgãos estaduais.

As desvantagens são geralmente relacionadas ao congestionamento de ações, que causam a morosidade e descredibilidade ao Poder Judiciário. Além disso, há a questão da litigância de má fé, que infelizmente é estimulada para obtenção de vantagens, bem como a falta de efetiva pacificação social, como bem discorre, (Tartuce, 2016): [...], existem necessidades suprimidas e a incapacidade de usar o sistema de jurisdição, e também há verificação inadequada de litígios inspirados por pessoas que usam a jurisdição nacional para obter diferentes benefícios [...]. Ainda em termos de incerteza, outra grave desvantagem da solução judicial nacional é a falta de alcance efetivo e pacífico para todas as partes.

Procedimento, Método ou processo; maneira através da qual alguma coisa é feita, comportamento ou conduta; maneira de se comportar. Mecanismos legais que colocam uma causa em juízo. Ação ou efeito de proceder. De sua origem visualiza-se seu significado, o modo de agir processual, a sucessão ordenada de atos à disposição para que se consubstancie a tutela jurídica. Procedimento configura-se na exteriorização e materialização do processo, podendo assumir diversos modos de ser (dicio.com.br/acesso 29/7/2017).

A conciliação pode ocorrer judicial ou extrajudicialmente, mesmo no decurso do processo judicial, pode acontecer um acordo extrajudicial, quando as partes entram num consenso, após homologam junto ao poder judiciário. As formas de conciliação judicial, a qual trata o trabalho ocorrem nos Juizados especiais (procedimento especial) e no juizado especial cível (procedimento ordinário). Segundo (Tartuce, 2016) A lógica de consenso (coexistência ou mediação) se aplica em ambiente de cunho colaborativo: onde as pessoas dialogam sobre as problemáticas onde não abordam somente o passado, mas também o futuro.

No Juizados especiais, o cidadão poderá valer-se de dois modos para ingressar com reclamação: através de petição inicial formulada por um advogado, pela Defensoria Pública ou por meio do serviço de atermação, que é um dos meios de acesso à Justiça pelos Juizados Especiais, em que o cidadão propõe uma ação independentemente de estar assistida por um advogado, observando que nem todo assunto pode ser tratado nos Juizados especiais, conforme cita a apostila do juizado especial cível de São Paulo (acesso 29/7/2017).

[...] ficam excluídas da competência do Juizado Especial as causas de natureza alimentar, fiscal e de interesse da Fazenda Pública e também as causas relativas a acidentes do trabalho, a resíduos (e outras questões testamentárias) e as causas relativas ao estado e capacidade das pessoas, ainda que de cunho patrimonial e as ações trabalhistas. Estão excluídas também as ações de procedimentos especiais que requerem ritos incompatíveis com o do Juizado Especial. O caput do art. 8. ${ }^{\circ}$ da Lei 9099/95 estabelece que nos Juizados dos Estados, do Distrito Federal e dos territórios não poderão ser partes (autor ou réu) o incapaz, o preso, as pessoas jurídicas de direito público, as empresas públicas da União, a massa falida e o insolvente civil.

O servidor ou colaborador reduzirá os relatos e pedidos da parte a termo (por escrito) e distribuirá o processo no Sistema PJE (Processo Judicial Eletrônico), o qual irá automaticamente para um dos Juizados Especiais Cíveis da comarca, já indicando qual cartório, data e hora da audiência, o requerente já sai intimado da mesma. O cartório o qual foi distribuído a ação, fara os expedientes necessários para citação e intimação dos requeridos. 
Nada impede que a parte traga a petição inicial já redigida, impressa e devidamente assinada, hipótese em que o servidor distribuirá, esse é o momento inicial do processo.

Após iniciado o processo, é citado a parte requerida para comparecer à audiência. A audiência de Conciliação, marcada pela oralidade, conduzida por conciliadores, nomeados pelo próprio juízo, com qualificações profissionais e requisitos objetivos previstos em Resoluções Internas do Tribunal correspondente. $\mathrm{Na}$ maioria dos casos, os conciliadores são selecionados, preferencialmente, bacharéis em direito, mas também com outra formação. Caso o acordo seja atingido, automaticamente, será redigido em ata e encaminhado ao cartório, para ser necessariamente homologado pelo magistrado competente, para seu devido cumprimento. Em caso de não haver acordo a ação seguirá para audiência de instrução e julgamento, sentença.

Na conciliação, havendo acordo, além da redução no tempo processual, a decisão foi um consenso entre as partes, cada uma cede um pouco para poder cumprir o avençado. Enquanto que no processo que vai para decisão do Magistrado, além da demora aumenta os custos para as partes e ainda tem o risco, da parte economicamente mais fraca, desistir da ação ou ainda não conseguir cumprir a decisão judicial.

Ocorre nas hipóteses previstas no art. 331 do CPC, isto é, quando não houver extinção do processo ou o julgamento antecipado da lide, e versar a causa sobre direitos que admitam transação (direitos disponíveis), o juiz designará audiência preliminar, a realizar-se no prazo de 30 (trinta) dias, para a qual as partes serão intimadas a comparecer, podendo fazer-se representar por procurador ou preposto, com poderes para transigir.

Neste caso, a conciliação em regra, é conduzida por um conciliador ou juiz togado, e, seguindo a mesma sistemática da Audiência de Conciliação Prévia nos juizados especiais, em havendo acordo, sua validade e eficácia como título judicial dependerá da sua homologação pelo juiz competente para o julgamento da causa.

No entanto, a prática demonstra que os acordos em processos sob o rito ordinário são mais difíceis de ser obtidos, visto que muitas ações são de grandes empresas públicas ou privadas, onde normalmente estes representantes dependem de normas externas ou já existe um limite de proposta predeterminado pela empresa, ou nenhuma proposta. Com bem mostra Bergamaschi, 2015, p. 168, citado por (Tartuce, 2016) Uma vantagem usualmente apontada por consenso é que as partes podem construir autonomamente uma resposta ao litígio sem ter que cumprir a resolução legal do conflito, sendo a vontade das partes o principal critério. Quando se trata de entidades públicas de previdência, o princípio da legitimidade administrativa mostra, sem dúvida, que o único padrão possível para a resolução de conflitos por consenso é a lei, pois o departamento administrativo não pode escapar da legitimidade e escolher outra base de negociação e composição. (Bergamaschi, 2015).

Outras situações, os prepostos sequer sabem do que trata a ação, posto que são indicados para o ato, quase no horário da audiência. Outra situação, talvez a mais difícil de lidar, é em relação a mentalidade de alguns operadores do direito, que ainda primam pela sentença. Em relação a esse tipo de mentalidade a autora (Tartuce, 2016). Pode-se dizer que, quando um advogado apresenta resistência em diálogos nos quais sujem para findar um acordo, fica claro que esse acaba por demostrar uma postura incompatível com sua função. Constata-se que é de suma importância para o profissional manter sua conduta em constante atualização social. vista disso, ocorre que o advogado primordialmente deve ser um negociador de intrigas eficiente.

Nesse seguimento, não havendo o acordo, o processo vai para instrução e julgamento, mas ainda assim, o juiz tenta nova conciliação, não conseguindo, é colhido prova em audiência e proferido a sentença, que será procedente ou improcedente ou ainda procedente em parte. O processo pode acabar logo após a sentença, se não houver recurso, como pode demorar na espera de julgamento de recursos, e se prolongar até o STJ e STF.

Após, o transito em julgado, vem o cumprimento de sentença, em duas modalidades: obrigação de fazer ou não fazer e obrigação de dar coisa certa ou incerta, desses procedimentos até o arquivamento, passará por Alvará, RPV ou precatório, (adaptado do jef.trf5-acesso 2017). Outra situação é em ralação a Lei 3.896/2016, que dispõe sobre cobranças de custa, nos 
termos do art. 12, inc. I, em caso de não havendo a autocomposição entre as partes, será cobrado do autor, mais $1 \%$ sobre o valor da causa a título de custas iniciais.

Foi informado que devido ao uso de ferramentas técnicas no processo eletrônico, não há necessidade de suspender os prazos dessas ferramentas. Tem-se a atenção voltada a manter o método evolutivo de forma segura. [...] o uso de ferramentas técnicas como videoconferência e teletrabalho para fornecer jurisdição à comunidade será de grande ajuda "(Cruz, 2020).

\section{Conclusão}

O Presente trabalho, foi um estudo sobre a solução de conflitos, por meio de acordo ou sentença, onde foi possível responder o questionamento para quem seria vantagem no acordo e, categoricamente respondeu que é vantajoso tanto para o requerente quanto para o requerido. Em face dos dados apresentados, foi possível concluir que há vantagens nos processos com acordo, em relação ao tempo, pois se inicia e termina em curto prazo, e em relação aos custos processuais, que são menores, os valores obtidos nos acordos, são muito próximo dos valores sentenciados. Em virtude do que foi mencionado, as desvantagens podem ser consideradas desprezíveis, já que o processo com pedidos improcedentes não tem como ser resolvido por meio da autocomposição.

Ficou evidenciado as vantagens do acordo, mas necessita de um programa de sensibilização para os operadores do direito bem como para a sociedade em geral, o que poderá ser realizado por meio de "outdoor", colocado nos fóruns bem como, enviar panfletos junto as citações e intimações das referidas audiências.

Esta pesquisa chama atenção às academias de Direito para que incluam nas grades curriculares, de forma transversal os meios alternativos nas resoluções do conflito. Para sociedade há ganho no sentido de que na resolução em conciliação das causas menores, haverá maior disponibilidade para os magistrados na resolução de processos complexos.

A sociedade capitalista só se sensibiliza, quando visualiza as informações de forma quantificada, portanto a lacuna deixada por esta pesquisa e que deve ser buscada por outros pesquisadores meios de transformar as vantagens de tempo e de custos, apresentados neste estudo, em valores reais, sendo esta, uma forma de sensibilizar para importância da conciliação usando uma linguagem conhecida por todas as classes sociais.

\section{Referências}

Boscatto, N. A. (2020, October). Mediação digital em tempos de pandemia covid-19. In XIV Mostra de Iniciação Científica e Extensão Comunitária e XIII Mostra de Pesquisa de Pós-Graduação IMED 2020.

Brasil. (1967). Constituição (1967). Constituição da República Federativa do Brasil. Senado.

Brasil. (1988). Constituição da República Federativa do Brasil. Senado.

Brasil. (2013) Dispõe sobre o Código Civil Brasileiro. Lei N. ${ }^{o} 10406$, de 10 de janeiro de 2002 Vade mecum. (4a ed.), Revista dos Tribunais. 956.

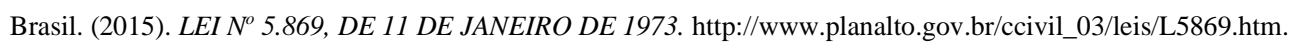

Brasil. (2016). Código de Processo Civil. Lei $n^{\circ} 13.105$, de 16 de março de 2015. Vade mécum Saraiva. (21a ed.), Saraiva.

Cahali, F. R. (2012) Curso de arbitragem. (2a ed.) Rev. dos Tribunais.

Conciliação e Definição de Metas Modernizaram Judiciário. http://www.cnj.jus.br/noticias/71011-conciliacao-e-definicao-de-metas-modernizaram-judiciario.

Conheça as vantagens de obter um acordo na Justiça. http://www.cnj.jus.br/noticias/judiciario/74473-quero-conciliar-esclareca-suas-duvidas

Constituição Brasileira (1967). http://www.inap.mx/portal/images/pdf/lat/brasil/constitucion\%20de\%20brasil\%201967.pdf.

Cooper, D. R., \& Schindler, P. S. (2016). Métodos de Pesquisa em Administração (12a ed.), McGraw Hill Brasil.

Corregedoria Destaca Efeitos de Provimento Nos Juizados Especiais. www.tjro.jus.br/corregedoria/index.php/advogado-e-cidadao/103-ultimas-noticias/2096corregedoria-destaca-efeitos-de-provimento-nos-juizados.

Cruz, Felipe Santa. (2020). Justiça em tempos de pandemia. Blog Fausto Macedo. 
Research, Society and Development, v. 10, n. 6, e39510615522, 2021

(CC BY 4.0) | ISSN 2525-3409 | DOI: http://dx.doi.org/10.33448/rsd-v10i6.15522

Diniz, M H. (2015) Curso de Direito Civil Brasileiro - Responsabilidade Civil. (29a ed.), Saraiva.

Escola Nacional de Mediação e Conciliação. (2012). Manual de Mediação Judicial. Ministério da Justiça.

Fiss, O. M. (2004) Um novo Processo Civil. Estudos Norte-Americanos sobre Jurisdição, Constituição e Sociedade. São Paulo: Editora Revista dos Tribunais.

Freitas, E. C. D., Prodanov, C. C. (2013). Metodologia do trabalho científico [recurso eletrônico]: métodos e técnicas da pesquisa e do trabalho acadêmico 2. ed. Novo Hamburgo. Feevale.

Gil, A. C. (2008). Metodologia do conhecimento cientifico. (6a ed.), Atlas S. A.

Holanda F. A. B. D. Mediação. Novo Dicionário Aurélio. On-line. https://www.dicio.com.br/procedimento.

http://www.mppe.mp.br/siteantigo/siteantigo.mppe.mp.br/uploads/pJ4Gnc7oUa1lMFee4fy4g/LiVOHWKye1WbOIFuhhXWGg/REsp_1129881_-RJ.pdf.

Iwakura, Cristiane Rodrigues. Conciliar é legal? https://jus.com.br/artigos/17035/conciliar-e-legal.

Manual de Mediação Judicial, Conselho Nacional de Justiça. http://www.cnj.jus.br/files/conteudo/arquivo/2016/07/f247f5ce60df2774c59d6e2dddbfec54.pdf.

Material de apoio. http://www.tjsp.jus.br/Download/Conciliacao/Apostila_Juizados_Especiais_Civeis.pdf.

Negrão, T. (2017). código de processo civil e legislação processual em vigor. Saraiva Educação SA.

Objetivos. https://www.tjro.jus.br/mn-nupemec-presentacao/mn-nupemec-objetivos.

Oliveira, M. B. B. D., Souza, M. C. D., (2011) O instituto da conciliação e sua importância para a efetiva prestação jurisdicional: estudo sobre o mutirão “Conciliar também é seguro" do Fórum Clóvis Beviláqua. In: Âmbito Jurídico, Rio Grande, XIV, n. 87.

Provasi, G. (2017) Danos Morais e Materiais: Qual a diferença entre eles? http://osdanosmorais.com.br/danos-morais.

Ritos dos Juizados. http://jef.trf5.jus.br/orientacaoCidadao/ritoJuizados.php.

Scavone, J. L. A., (2014) Manual de Arbitragem. (5a.ed.), Forense.

Significado de Danos morais. https://www.significados.com.br/danos-morais/.

Superior Tribunal de Justiça.

Tartuce, F. (2016) Mediação nos Conflitos Civis. (3a ed.), Forense. MÉTODOS. 